\title{
Article
}

\section{The Effect of Fusarium verticillioides Fumonisins on Fatty Acids, Sphingolipids, and Oxylipins in Maize Germlings}

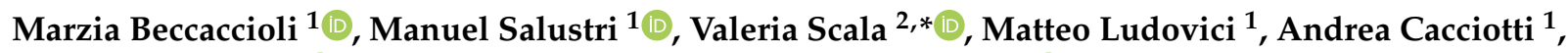 \\ Simone D'Angeli ${ }^{1}{ }^{(}$, Daren W. Brown ${ }^{3}$ and Massimo Reverberi ${ }^{1}{ }^{1(0)}$ \\ 1 Department of Environmental Biology, University of Rome "Sapienza", 00185 Rome, Italy; \\ marzia.beccaccioli@uniroma1.it (M.B.); manuel.salustri@uniroma1.it (M.S.); ludovicim@hotmail.it (M.L.); \\ andrea.cacciotti@uniroma1.it (A.C.); simone.dangeli@uniroma1.it (S.D.); \\ massimo.reverberi@uniroma1.it (M.R.) \\ 2 Centro di Ricerca Difesa e Certificazione, Consiglio per la Ricerca in Agricoltura e l'Analisi dell'Economia \\ Agraria, 00156 Rome, Italy \\ 3 United States Department of Agriculture, Agriculture Research Service, Peoria, IL 61604, USA; \\ Daren.Brown@ars.usda.gov \\ * Correspondence: valeria.scala@crea.gov.it; Tel.: +39-06920701
}

check for updates

Citation: Beccaccioli, M.; Salustri, M.; Scala, V.; Ludovici, M.; Cacciotti, A.; D'Angeli, S.; Brown, D.W.; Reverberi, M. The Effect of Fusarium verticillioides Fumonisins on Fatty Acids, Sphingolipids, and Oxylipins in Maize Germlings. Int. J. Mol. Sci. 2021, 22, 2435. https://doi.org/ $10.3390 /$ ijms 22052435

Academic Editor: Alessio Mengoni

Received: 22 January 2021

Accepted: 23 February 2021

Published: 28 February 2021

Publisher's Note: MDPI stays neutral with regard to jurisdictional claims in published maps and institutional affiliations.

Copyright: (c) 2021 by the authors. Licensee MDPI, Basel, Switzerland. This article is an open access article distributed under the terms and conditions of the Creative Commons Attribution (CC BY) license (https:/ / creativecommons.org/licenses/by/ $4.0 /)$.

\begin{abstract}
Fusarium verticillioides causes multiple diseases of Zea mays (maize) including ear and seedling rots, contaminates seeds and seed products worldwide with toxic chemicals called fumonisins. The role of fumonisins in disease is unclear because, although they are not required for ear rot, they are required for seedling diseases. Disease symptoms may be due to the ability of fumonisins to inhibit ceramide synthase activity, the expected cause of lipids (fatty acids, oxylipins, and sphingolipids) alteration in infected plants. In this study, we explored the impact of fumonisins on fatty acid, oxylipin, and sphingolipid levels in planta and how these changes affect $F$. verticillioides growth in maize. The identity and levels of principal fatty acids, oxylipins, and over 50 sphingolipids were evaluated by chromatography followed by mass spectrometry in maize infected with an F. verticillioides fumonisin-producing wild-type strain and a fumonisin-deficient mutant, after different periods of growth. Plant hormones associated with defense responses, i.e., salicylic and jasmonic acid, were also evaluated. We suggest that fumonisins produced by F. verticillioides alter maize lipid metabolism, which help switch fungal growth from a relatively harmless endophyte to a destructive necrotroph.
\end{abstract}

Keywords: lipids; sphingolipids; mycotoxins; programmed cell death; necrotroph; salicylic acid

\section{Introduction}

Fungi derive nutrients from plants passively as biotrophs, aggressively as necrotrophs, or as hemibiotrophs in which the fungus first establishes itself in host tissue causing little damage followed by a switch to a destructive, necrotrophic lifestyle [1]. Although such classifications are useful, they are simplistic and somewhat arbitrary. Indeed, some fungi have been associated with all three growth strategies [2]. For example, Fusarium verticillioides is considered a hemibiotroph, co-exists with Zea mays (maize) as an endophyte while, on occasion, it is able to switch to a necrotroph and cause disease at any life stage of the plant $[3,4]$.

What triggers this infrequent change in lifestyle is unknown, although it may be related to drought or heat stress or physical damage caused by insects or hail [5]. A frequent co-occurrence with pathogenic growth in infected maize is the production of fumonisins (FBs), a family of highly toxic secondary metabolites. Consumption of FB contaminated foods and feed is associated with a variety of animal diseases and is epidemiologically associated with esophageal cancer in humans [6-9].

The co-occurrence of disease and FBs suggest that they are associated. An early study found that a non-producing fumonisin strain of F. verticillioides caused ear infection and 
ear rot of maize, indicating that they are not related [10]; more recent studies support a role for FBs in pathogenesis. For example, in F. verticillioides, a mutation in FUM1, a polyketide synthase necessary for fumonisins production, generate a mutant less virulent to maize seedlings [11]; in F. musae, a strain enabled to synthesize FBs became pathogenic to seedlings [12,13]; and in F. proliferatum, fumonisin-deficient strains display significantly decreased pathogenicity to rice [14]. The impact of FBs on disease is likely due to their ability to inhibit ceramide synthase (CerS), a key enzyme in sphingolipid biosynthesis. Could the changes in plant metabolism of lipids caused by FBs trigger the fungus to transition from endophytism to necrotrophy? Sphingolipids are a diverse group of compounds that function as anchors for membrane proteins [15] and as secondary messengers for multiple cellular functions $[16,17]$. CerS forms an amide bond between the amine group on the sphingoid base, referred to as a long-chain base (LCB), and the carboxylic group of a fatty acyl-CoA [18]. Fatty acids with between 12-18 carbons (C12-C18) are called long-chain fatty acids (LCFAs) and chains between 20-36 carbon (C20-C36) are called very long-chain fatty acids (VLCFAs). Both the LCB and the fatty-acid chain can be further modified leading to even more sphingolipid structural diversity.

Perturbations in sphingolipid metabolism and programmed cell death (PCD) in plants are linked [19]. FBs, the structurally related fungal chemical AAL toxin, produced by Alternaria alternata, sphingolipid metabolism inhibitors induce the accumulation of LCBs, which in turn cause PCD $[7,20]$. PCD is dependent on the hormones ethylene, jasmonic acid (JA), and salicylic acid (SA) [21-24]. PCD may also be triggered by changes in ceramide levels. A thaliana mutant acd5 (encoding a ceramide kinase) accumulated ceramides prior to PCD, which was attenuated by the addition of phosphate ceramides [25]. The ceramidetriggered PCD may, in turn, be influenced by fatty acid chain length. Depletion of VLCFA ceramides can impair plasma membrane organization leading to reduced pathogenic responses and cell death [26,27].

The role of hormones (i.e., SA and JA) in helping fungi resist PCD caused by biotrophic and hemibiotrophic pathogens is crucial because they can induce production of defense proteins and other chemicals. For example, SA may induce production of the antifungal protein (PR1) as well as different enzymes involved in phytoalexin synthesis such as phenylalanine ammonia-lyase (PAL). Phenols, including the phytoalexins, are key molecules in the primary inducible response in plant defense. JA, which is produced in response to the necrotrophic pathogens, may induce the expression of the chitinase PR4 as well as several enzymes that promote lipid peroxidation including lipoxygenases (LOXs) and allene oxide synthases (AOSs). The cross-talk between SA and JA provide plants, through PCD, tools to restrict the growth of biotrophic and necrotrophic pathogens and limit their negative impact [28-30].

Fatty acids (FAs) may regulate the signal transduction as a consequence of environmental and developmental stimuli. FAs are play important roles in the membrane composition and fluidity as well as intracellular signaling which impact the plants immune responses [31]. Length, desaturation grade, and quantity are important parameters to determine the cellular response during plant-microbe interactions. For example, fatty acid synthesis can depend on the presence of palmitoleic acid (16:1) produced by the plant during the interaction of arbuscular-mycorrhizal fungi [32]. Furthermore, enhanced levels of palmitoleic acid (16:1) can confer resistance to pathogenic fungi [33]. Seed fatty acid composition is also suggested to be a component of pathogen susceptibility and seed colonization; in fact, reduced levels of oleic acid (18:1) results in the constitutive activation of defense responses [31,32].

Among the membrane lipids are the polyunsaturated FAs (PUFAs), which may be released in response to a pathogen attack. PUFAs may act as free FAs or as oxylipins or oxygenated FAs. During the infection process, initial plant defenses are activated by the detection of reactive oxygen species which promote lipid peroxidation and the formation of oxylipins. Among the oxylipins, JA elicits the plant defenses against biotrophic pathogens. Oxylipins are also produced by the fungi, influencing mycelial growth and 
spore germination. In Aspergillus spp., linoleic acid (18:2) influences development, seed colonization, and mycotoxin production $[33,34]$.

In the present study, we evaluated the abundance of more than 50 sphingolipids including sphingoid bases, ceramides, and phytoceramides, in maize infected with an FB-producing F. verticillioides (wild-type) and an FB non-producing mutant (fum1 $1 \Delta$ ), in which the fum 1 gene was deleted. We found that VLCFA containing sphingolipids were negatively impacted by FBs produced by the wild-type strain in infected maize while LCFA containing sphingolipids were positively impacted, compared to fum $1 \Delta$ mutant infected maize. Lipid content can explain the pathogenic efficacy [17]; therefore, the fatty acids and oxylipins have been evaluated for the regulatory role during plant-pathogen interaction. We also evaluated the production of SA and JA in maize. We suggest that during the interaction between the host and F. verticillioides, the modification of sphingolipid and plant defense responses are associated with the fumonisin production and modulate the endophytic growth of $F$. verticillioides into a necrotrophic growth typical of rotting diseases.

\section{Results}

\subsection{Infection of Maize Kernel with F. verticillioides Wild-Type and Fumonisin Non-Producing} Mutant fum1 $1 \Delta$

Maize kernels infected with the $F$. verticillioides wild-type or mutant fum $1 \Delta$ was maximal at 14 days after infection (dai) (Figure 1a-f). To understand the influence of fungal growth on seed germination, the length of roots and stems was evaluated. However, no significant difference was observed in root and stem length in 14-day seedlings infected (Figure 2a).
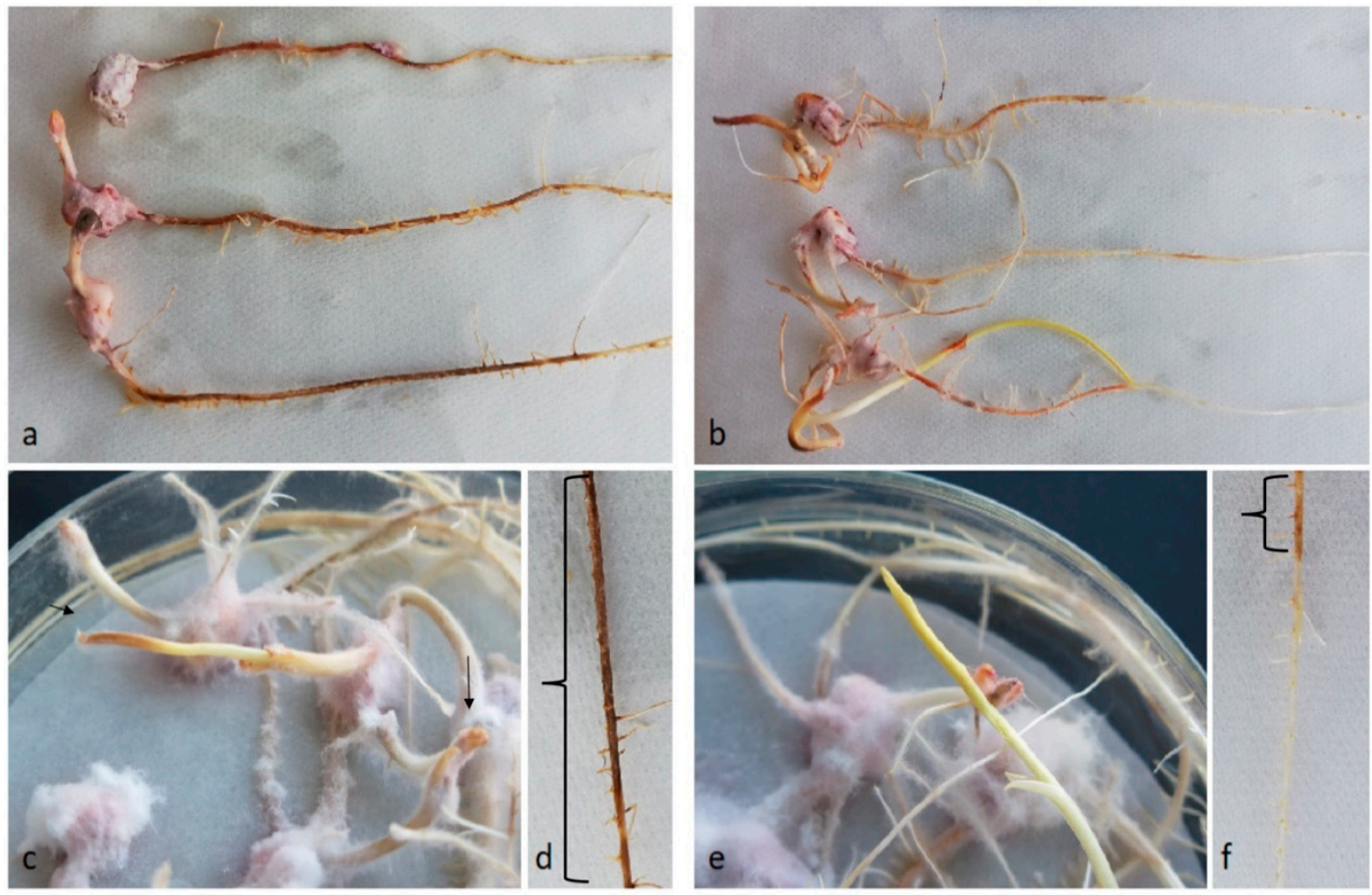

Figure 1. Seedling shoots and roots showing necrotic areas caused by infection with Fusarium verticillioides wild-type (wt) or fum1 deletion mutant (fum1 1 ) strains. (a) wt and (b) fum1 1 infected seedlings at 14 days after infection (dai); close view of typical shoots and the necrotic portion of the roots in wt- $(\mathbf{c}, \mathbf{d})$ and in fum $1 \Delta$ infected seedlings (e,f) with (the necrotic areas are indicated by the arrows-in the shoots-and between brackets-in the roots). 
a)

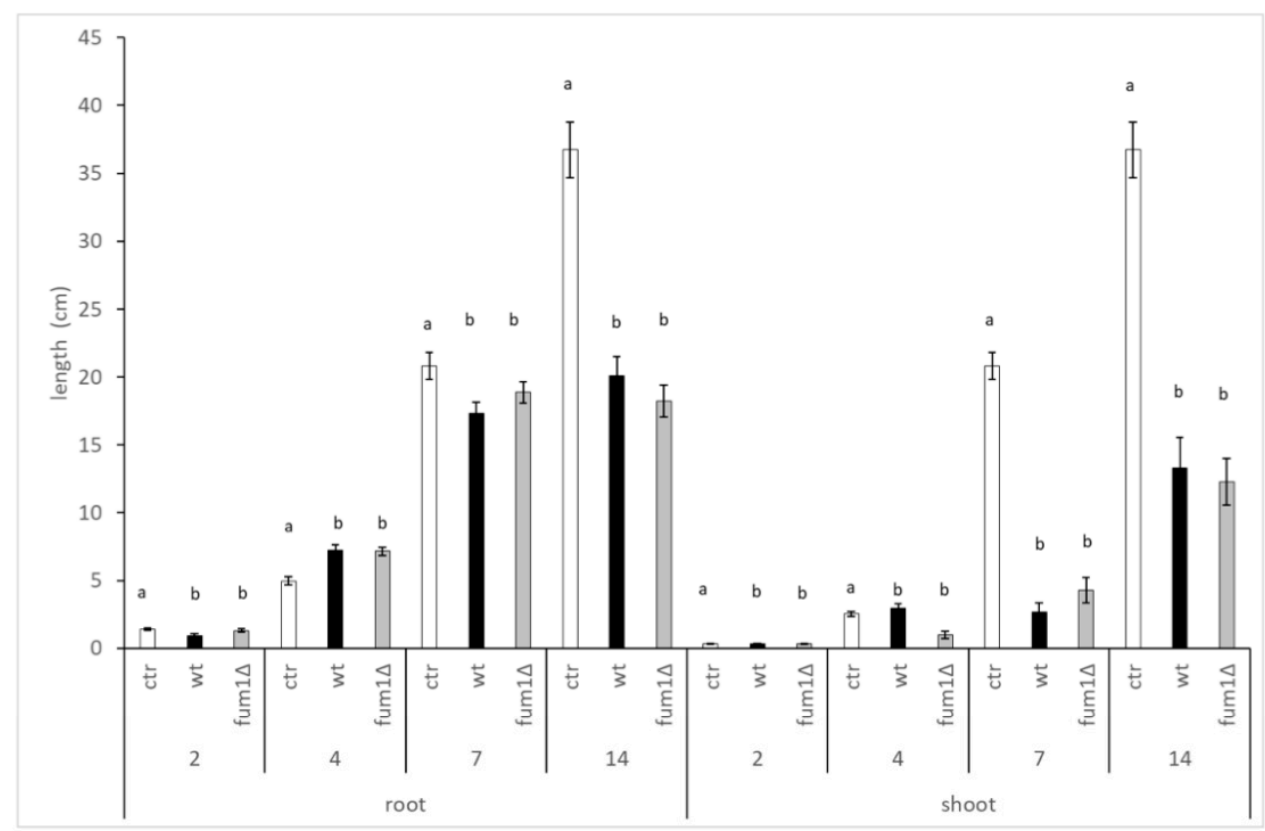

b)

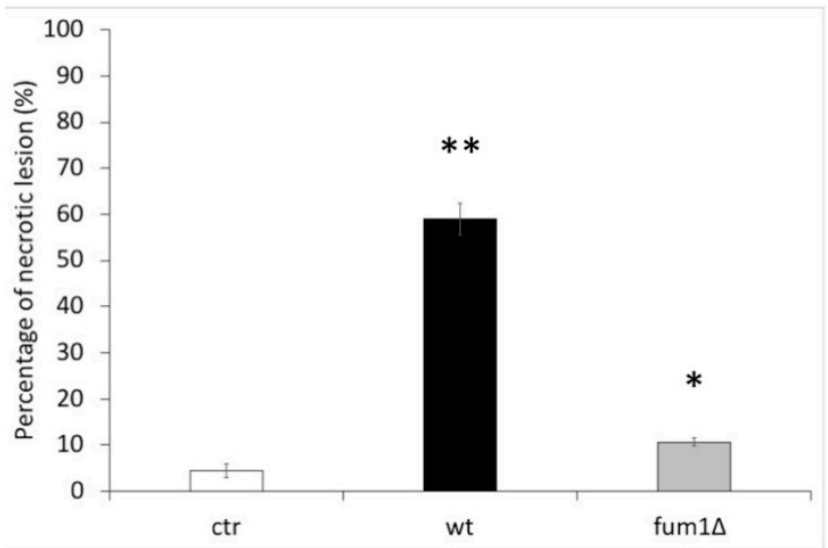

c)

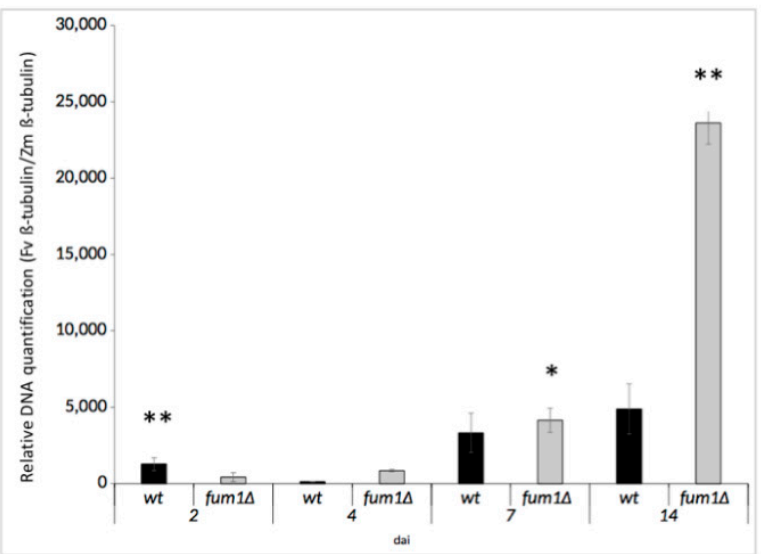

Figure 2. (a) Root and stem elongation in maize kernels mock-infected (ctr) or infected with F. verticillioides wild-type (wt) or mutant (fum1 $\Delta$ ) after 2, 4, 7, and 14 days after infection (dai). Data are presented as the mean from two experiments, $\mathrm{n}=20$ seeds, results are the mean \pm std error. Significance $(p \leq 0.05)$ was assessed by one-way ANOVA followed by Tukey's test (groupings indicated by a,b). (b) number of roots showings symptoms of necrosis at 14 dai in the non-infected control (ctr), wt, and fum $1 \Delta$ infected seedlings. (c) DNA extracted from infected and non-infected seedlings at 2, 4, 7, and 14 dai was examined by qPCR with primers specific to F. verticillioides and Z. mays genes coding for $\beta$-tubulin. Total height of each bar indicates the quantity of fungal DNA relative to the total DNA detected. Asterisks indicate a significant difference at same time point from $\mathrm{ctr}$ in (b) and from the wt in (c) (Student's t-test: ${ }^{*} p<0.05$; ${ }^{* *} p<0.01$ ).

Consistent with previous work [35] showing that $F$. verticillioides may cause necrotic lesion [35], we observed more necrotic lesions in wild-type infected roots than in fum1 $\Delta$ infected roots (Figure $1 \mathrm{~d}$ and $\mathrm{f}$ and Figure $2 \mathrm{~b}$ ). The differences in disease symptoms that we saw did not appear to be related to the amount of pathogen presence, as determined by qPCR. The amount of genomic DNA detected was higher for fum $1 \Delta$ than the wild-type infected maize (Figure 2c). 


\subsection{Fumonisin Contamination and Lipid Compounds}

Lipid entities present during the maize kernel infected with the F. verticillioides wildtype or fum $1 \Delta$ mutant were evaluated. Correlation between lipid compounds and fumonisins contamination has already been considered [36]. A positive correlation was obtained between the fatty acids, oleic, and linoleic acid when the fumonisins contamination level was higher. However, the accumulation of fatty acids in the presence of a fumonisin non-producing F. verticillioides strain after significant growth has never been considered. FBs were first detected by high-performance liquid chromatography-mass spectrometry (HPLC-MS/MS) after 4 dai and reached a maximum at 14 dai (Figure 3). In general, the number of lipids in infected seedlings was significantly altered compared to the control seedlings, regardless of the presence of the FBs (Table S1). Specifically, differences between the wild-type and fum $1 \Delta$ infected seedlings depend on the length of infection. FA C16:1 and, in general, the C18 FAs undergo a substantial change at 4 dai-they decreased in the wild-type-infected seedlings compared to the fum $1 \Delta$-infected ones (Table S1). At 14 dai, C16:1, C18:0, and C18:2 FA significantly increased in the wild-type-infected seedling, even in comparison with the control and, intriguingly with the fum $1 \Delta$-infected seedlings (Figure 3). The presence of FBs is positively correlated to the increase of FAs in maize; these results are consistent with previous ones [37].
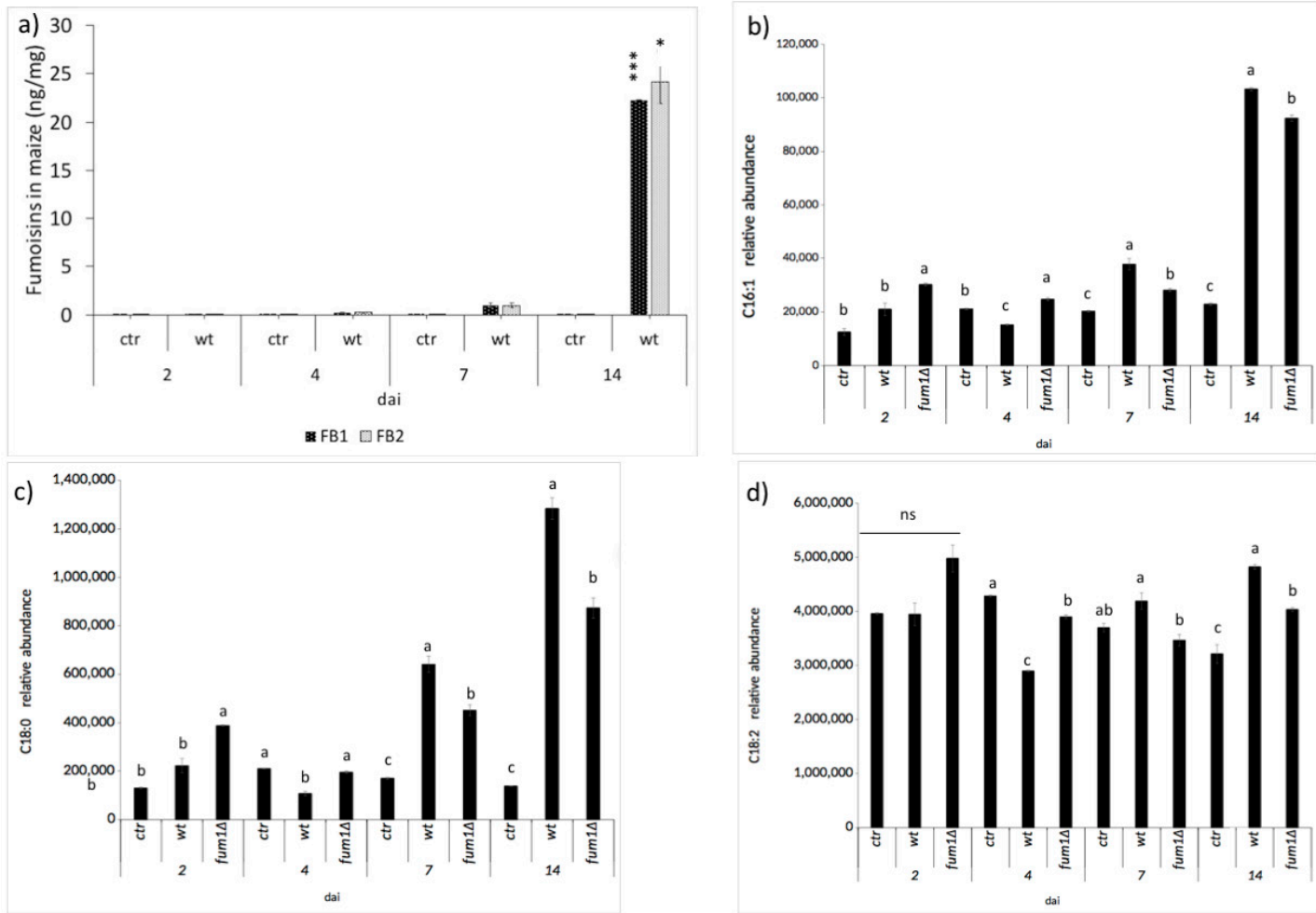

Figure 3. Toxin and fatty acid content were evaluated in seedlings non-infected (ctr) and infected by wild-type (wt), or by fum1 deletion mutant (fum1 1 ). (a) Fumonisins (FB1 and FB2) in wt-infected and in the ctr seedlings at several days after infection (dai) analyzed by an MRM (Multiple Reaction Monitoring) approach with HPLC-MS/MS. The error bars represent standard error calculated from three independent replicates, technically repeated in triplicate. Asterisks indicate a significant difference at same time point from $\operatorname{ctr}$ (Student's $t$-test: ${ }^{*} p<0.05 ;{ }^{* * *} p<0.001$ ). (b) C16:1 (c) C18:0 (d) C18:2 fatty acids in infected (wt or fum1 $\Delta$ ) and ctr seedlings at several dai analyzed by a single ion monitoring (SIM) with HPLC-MS/MS. The error bars represent standard error calculated from three independent replicates, technically repeated in triplicate. Significance $(p \leq 0.05)$ was assessed by one-way ANOVA followed by Tukey's test.

The influence of FB synthesis on oxylipins production was also examined (Table S1). The oxylipin 9-HODE, an established mycotoxin-susceptibility factor [38], is produced by maize ears contaminated with fumonisins under field conditions [37]. Here we found 
9-HODE concomitant with FB biosynthesis (i.e., 7-14 dai; Table S1). We also report significative differences in seedlings infected with the naïve or the fum $1 \Delta$ strains in relation to the synthesis of the JA precursors, 13-HOTrE, 13-HpODE, and 13-HODE. Notably, these oxylipins were enhanced after growth of the fumonisin production strain in comparison to both fumonisin non-producing strain and the uninfected control. It was recently noted that jasmonates play a leading role in controlling $F$. verticillioides infection in maize $[35,37,39]$. Other oxylipins, such as 10-HpOME (by C18:1), 9,10-DiHOME (by C18:2), 9-oxoODE (by $\mathrm{C} 18: 2$ ), and 9-oxoOTrE (by C18:3), which seem to be linked to the precocious FBs accumulation, were detected at 7 dai, at least for the oxylipins derived from C18:2 and C18:3, as already suggested elsewhere [38,40].

\subsection{Maize and F. verticillioides Sphingolipidome Characterization}

The relationship between sphingolipids and fumonisins was tested by HPLC-MS/MS. To check and characterize the sphingolipids, a mass spectrometry method was conducted to evaluate LCBs, ceramides, phytoceramides, and dehydro-phytoceramides present in our pathosystem. The generated mass-spectra were analyzed by multiple reaction monitoring (MRM) approach. The identified compounds are listed and grouped in Table S2 according to whether they were detected in maize, in F. verticillioides, or in both. The analysis was performed in electrospray ionization source (ESI) positive ion mode. In general, the most abundant ion for sphingoid bases is the di-dehydrate ion $\left[\mathrm{M}+\mathrm{H}^{+}-2 \mathrm{H}_{2} \mathrm{O}\right]$ while the parental or molecular ion $\left[\mathrm{M}+\mathrm{H}^{+}\right]$is less abundant (Figure 4). Saturated C18 LCBs, such as sphinganine and phytosphingosine, exhibited a typical $60 \mathrm{~m} / \mathrm{z}$ fragment indicative of a trimethyl-ammonium moiety. Ceramides and phytoceramides exhibited a fragmentation pattern consistent with the loss of a single water moiety and include a cognate sphingoid base fragment as an amide bounded fatty acid ion. Glucosyl-ceramides harbor an additional glucose moiety that constitutes a neutral loss.

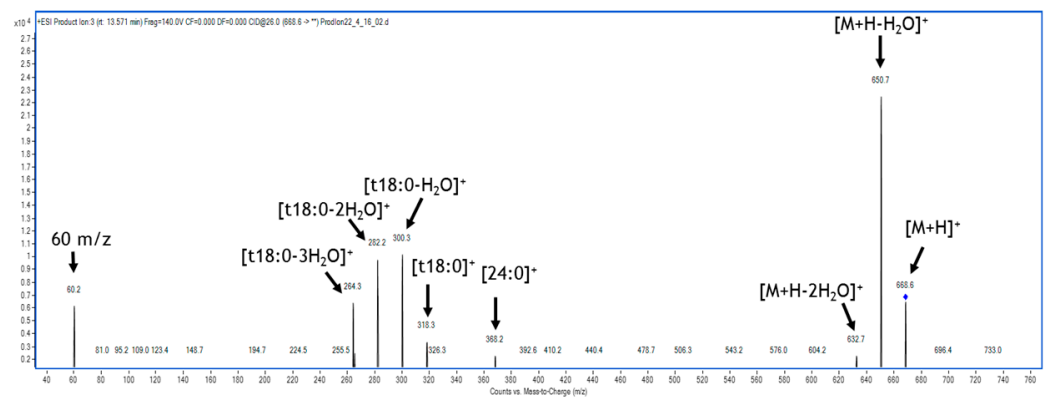

Figure 4. Example of fragmentation pattern for a sphingolipid. The phytoceramide with $\mathrm{m} / \mathrm{z} 667.6$ (t18:0) showed a clear fragmentation pattern with the $60 \mathrm{~m} / \mathrm{z}$ fragments typical of sphingoid bases.

Figure S1A,B is an overlay of total ion chromatograms from mock-infected maize and maize infected with $F$. verticillioides. Significant differences in the profiles were readily noted with ions of $\mathrm{m} / \mathrm{z} 506,680,710,736,754$, and 822 detected only in the infected maize while ions of $\mathrm{m} / \mathrm{z} 536,562,564,566,596,696,698,724,770,780$, and 808 detected only in mock-infected maize.

2.4. Sphingolipidome Characterization in Maize Kernels Infected with F. verticillioides Wild-Type and Fumonisin Non-Producing (fum1 $\Delta$ ) Mutant Strain

As noted, FBs, which F. verticillioides may produce while infecting maize, can inhibit the enzyme CerS and disrupt plant sphingolipid synthesis. Therefore, we reasoned that comparing lipids present in maize infected with an FB non-producing strain (fum1 $\Delta$ ) and a producing strain (wild-type) would reveal the affected lipid species (Figure $3 \mathrm{~b}-\mathrm{d}$ ). HPLCMS/MS and statistical analysis of maize seedlings mock-infected (ctr) and infected with the wild-type or fum $1 \Delta$ strains revealed that the presence and quantity of 13 sphingolipids were significantly different during the infection process (Figure S2). Maximal differences were observed at 14 dai (Figure 5). Sphingosine d18:1 has already demonstrated closely 
linked to PCD Arabidopsis [21], and our result in maize confirm this (Figure 5). Dihydroxy and trihydroxy LCFA containing sphingolipids (S-LCFAs) d18:0/16:0 (Figure 5), d18:2/18:1 (Figure 5), t18:0/16:0 (Figure 5), t18:1/16:0 (Figure 5) are similar in maize infected with the fum $1 \Delta$ strain or mock-infected and significantly greater in the wild-type-infected maize at 14 dai, and the VLCFA sphingolipid (S-VLCFA) t18:0/24:0 (Figure 5). The presence of FB synthesis can positively act on the synthesis of these sphingolipids. S-VLCFAs t18:2/22:0 (Figure 5), t18:0/26:0 (Figure 5), t18:0/h23:0 (Figure 5), and t18:0/h24:0 (Figure 5) increase in the maize kernel infected with fum $1 \Delta$ strain, suggesting that they are impacted by the presence of FBs, inhibiting the site of ceramide synthases.
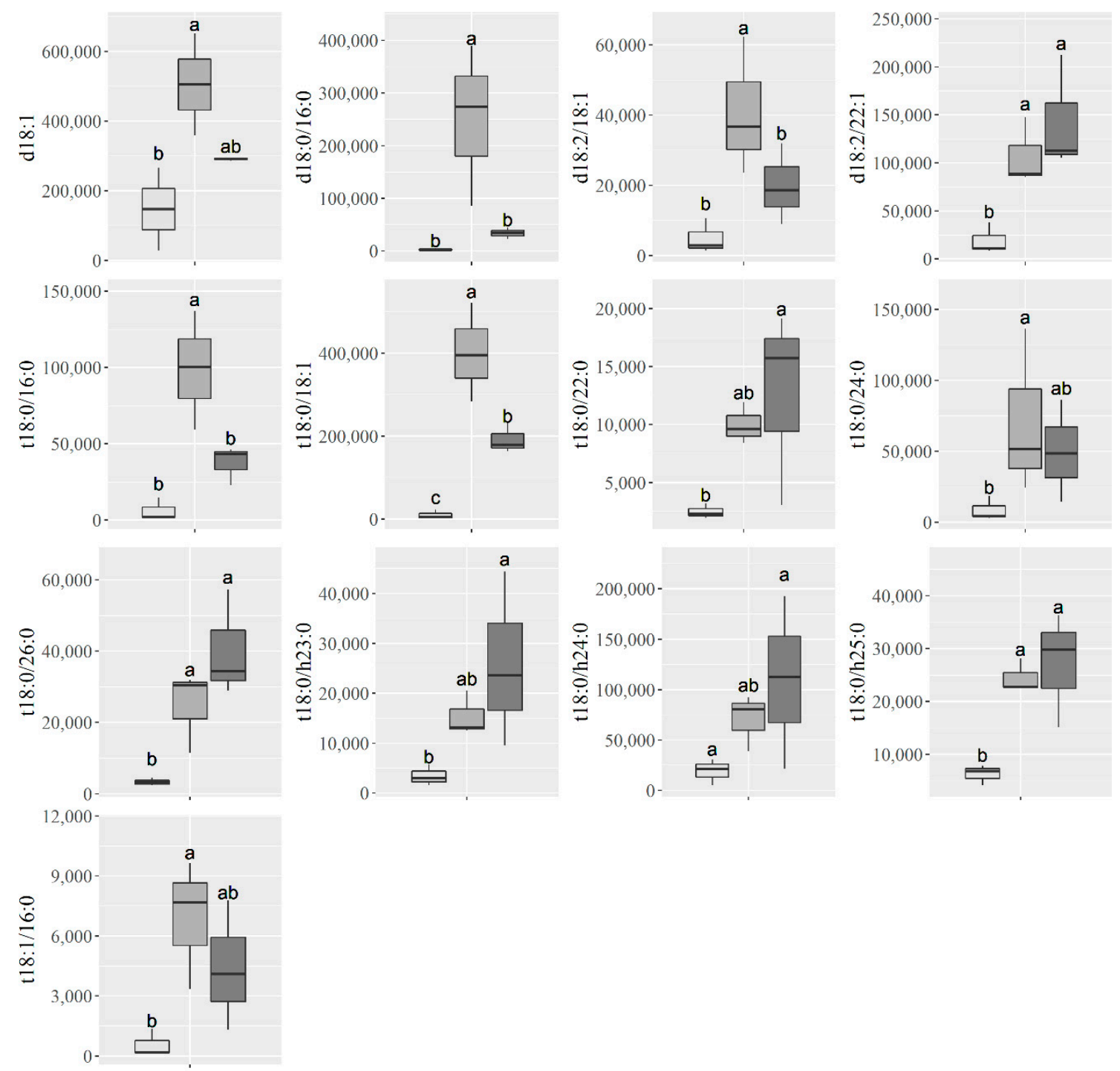

$$
\text { 追 } \mathrm{ctr} \text { 官 wt 官fumls }
$$

Figure 5. The relative abundance of different sphingolipids at 14 dai. Y-axis: relative abundance of compounds found in maize kernel mock-infected (ctr) and infected with F. verticillioides wild-type (wt) or fumonisin non-producing mutant fum1 $1 \Delta$, measured as normalized peak intensity. Box plot represents the distribution of the relative quantity of sphingolipids deriving from three independent replicates which were technically repeated in triplicate. Asterisks indicate statistically significant differences between infected-maize (wild-type or fum $1 \Delta$ ) and ctr at each time point. Significance $(p \leq 0.05)$ was assessed by one-way ANOVA followed by Tukey's test.

Only three sphingolipids were found to be present both in wild-type and fum $1 \Delta$ maize infected kernel: the ceramide d18:2/22:1 (Figure 5), the phytoceramides t18:0/18:1 (Figure 5), and t18:0/h25:0 (Figure 5). 


\subsection{The Balance between the Salicylic and Jasmonic Acid}

SA and JA are two crucial phytohormones involved in stress signaling and plant defense. In general, JA trigger and modulate plant resistance against biotrophic pathogens while the SA does so against the necrotrophic pathogens. Their balance and the influence of other hormones drive the defense response. In the cross-talk among SA and JA, several molecular mediators interact that drive the signal transduction. The interactions among these factors determine the plant's defense against specific aggressors.

SA and JA seem to have a synergistic or antagonistic interaction in plant disease and immune responses. Here we noted that SA accumulation started early after infection and continued through 14 dai (Figure 6a), while JA was present only at 7 dai and 14 dai (Figure 6b). However, the amount of JA and SA only became significant at 14 dai, when they were greater in wild-type-infected seedlings than they were in either the ctr and fum $1 \Delta$-infected seedlings. These results suggest that the concentration of JA and SA is dependent on the increase in fumonisins and that the synergic accumulation at 14 dai may be linked to the necrotrophic lifestyle.

a)

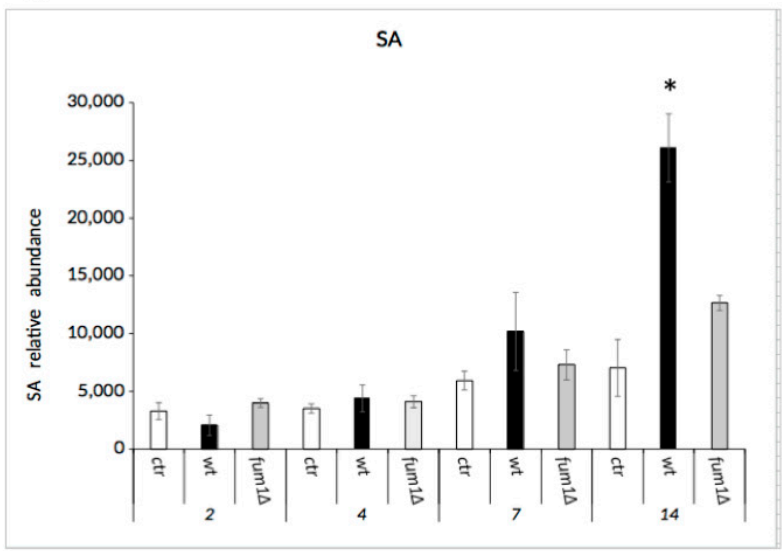

b)

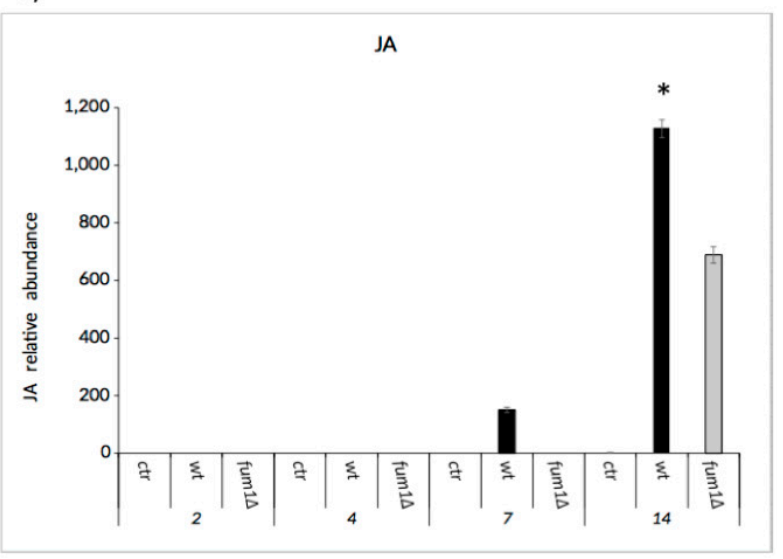

Figure 6. HPLC-MS/MS quantification of hormones. SA (a) and JA (b) in seedling infected by F. verticillioides wild-type (wt) or fum $1 \Delta$ strains compared to seedling not infected (ctr). Data represent the means \pm standard error of three technical replicates. Asterisks above the bars indicate a significant difference between the ctr and wt or fum $1 \Delta$ infected seedlings at the same time point (Student's $t$-test, ${ }^{*} p<0.05$ ).

\subsection{Exposure of Maize Protoplasts to FB1}

The PCD consists in the accumulation of antimicrobial compounds and in the formation of necrotic lesions to ensure pathogen containment. In addition, the SA induces apoptosis [41]. Maize protoplasts were exposed to a mixture of FB1 and FB2; after exposure, apoptotic and necrotic protoplasts have been counted. The percentage of apoptotic and necrotic cells was enhanced after the exposure (Table 1).

Table 1. Cell viability of protoplasts in the absence (Ctr) or presence of $25 \mathrm{ng}$ of $\mathrm{FBs}\left(\mathrm{FB}_{1}+\mathrm{FB}_{2}\right)$ Values represent the mean of triplicate experiments.

\begin{tabular}{ccccc}
\hline & \multicolumn{5}{c}{ \% Protoplasts } \\
\hline Treatment & Normal & Apoptotic & Necrotic \\
\hline ctr & 41 & 31 & 29 \\
\hline Maize Protoplasts $+\left(\mathrm{FB}_{1}+\mathrm{FB}_{2}\right)$ & 29 & $* * *$ & 36 & $* *$ \\
\hline
\end{tabular}

Student's $t$-test, ${ }^{*} p<0.05,{ }^{* *} p<0.01,{ }^{* * *} p<0.001$ applied to the compare maize protoplasts $+\left(\mathrm{FB}_{1}+\mathrm{FB}_{2}\right)$ to non-infected seed control (ctr). 


\section{Discussion}

F. verticillioides is most often a harmless endophyte of maize, but, in response to poorly understood biotic and abiotic factors, it can become a pathogen and derive nutrients as a destructive necrotroph [12]. Infected kernels, showing no or minimal disease may contain low levels of mycelia, while significantly diseased kernels are extensively colonized and are frequently contaminated with fumonisins (FBs), a family of mycotoxins that may cause significant harm to animals. What is the function of these chemicals and are they related to maize disease? Although FBs are not required for endophytic growth [42] nor for some ear-rot diseases [43], we and many others have found that they do play a role in seedling diseases of maize $[11,13,20,41,42,44]$.

Lipid entities present during the maize kernel infection are correlated to fumonisin contamination [39]. Here we observed a drastic increase of FBs and a significant increase of C16:1, C18:0, and C18:2 fatty acids (FAs) in the wild type-infected seedlings after 14 days infection (dai) (Figure 3b-d). In addition to their role in the onset of plant defenses [45], FAs serve as precursors for oxylipins. Numerous oxylipins function as signaling molecules and are intimately involved in the maize-F. verticillioides communication [36]. In our system, the mycotoxin-inducing oxylipin $9-\mathrm{H}(\mathrm{P}) \mathrm{ODE}$ is triggered upon fungal infection regardless of the ability of the fungus to produce (wild-type) or not (fum1 $\Delta$ ) fumonisins. Thus, we can infer and confirm its role as a mycotoxin regulator at least in this system. Most intriguingly, the wild-type strain stimulated synthesis of the plant hormone jasmonatic acid (JA) in maize seedlings better than the fum $1 \Delta$ strain. Based on this, it can be suggested that FBs can act as elicitors or enhancers of the plant hormones, SA, and JA (Figure 6).

Amongst lipid entities involved in the plant-fungal interaction, sphingolipids also play a crucial role. We found that FB synthesis and maize disease severity were connected by alterations in plant sphingolipids caused by the FB induced disruption of plant ceramide synthase activity. What are these changes? In Arabidopsis, FBs increase long-chain base (LCBs or sphingoid bases) levels, which induce PCD. FBs also disrupt sphingolipid metabolism in maize seedling, and the toxin increase causes an increase of free sphingoid bases [46]. Specific lipids, involved in triggering PCD as a consequence of FB phytotoxic effects, have not been well characterized to date.

To help clarify the relationship in maize between sphingolipids, fumonisins, and disease, we evaluated the relative abundance of more than 50 sphingolipids (Table S2), including different subtypes of sphingoid bases, ceramides, and phytoceramides, produced by both the host and the pathogen up to 14 dai (Figure S2 and Figure 5). We found (i) an increase of sphingoid base d18:0 in wild-type-infected maize, (ii) more S-LCFA sphingolipids, such as d18:0/16:0, d18:2/18:1, t18:0/16:0, t18:2/18:1, and t18:1/16:0, and one S-VLCFA t18:0/24:0 at 14 dai in wild-type-infected maize compared to mock-infected maize; and (iii) more S-VLCFAs, such as t18:0/22:0, t18:0/26:0, t18:0/h23:0,and t18:0/h24:0 in maize infected with the non-fumonisin producing mutant fum $1 \Delta$ compared to maize infected with the wild-type. The alterations caused by FBs on lipid metabolism generated an accumulation at 14 dai in the wild-type-infected kernel of the ceramides and phytoceramides containing LCFA.

What are the modulators of sphingolipids in plants? In Arabidopsis thaliana, three isoforms ( $\mathrm{LOH} 1, \mathrm{LOH} 2$, and $\mathrm{LOH} 3$ ) are present. The ceramide synthase $2(\mathrm{LOH} 2)$ preferentially acylates sphinganine with $\mathrm{C} 16$ fatty acids, while ceramide synthase 1 and 3 ( $\mathrm{LOH} 1$ and $L O H 3$ ) acylate phytosphingosine with VLCFA $[47,48]$. The accumulation of S-LCFA in the wild-type-infected kernel and the accumulation of S-VLCFAs in maize infected with $F$. verticillioides fum $1 \Delta$ suggests that FBs produced by the fungus could target maize homologs of $\mathrm{LOH} 3 / \mathrm{CerS} 2$ over other isoforms of CerS, thereby reducing the S-VLCFA synthesis and $\mathrm{LOH} 2$ to enhance the amount of S-LCFA. What is the resulting phenotype of these alterations in the sphingolipidome in our system? Probably, it is an increase of necrotic areas in the roots of the maize seedlings infected with the FB-producer, i.e., the wild-type strain. Supporting this hypothesis, FB that was provided to protoplasts obtained from our system enhanced the apoptotic/necrotrophic events, as also verified by other authors in 
Arabidopsis [22]. Thus, we can hypothesize that FB-driven massive increase of sphingoid bases and S-LCFA and a concomitant decrease of S-VLCFA represent key signals that can control PCD in maize seedlings. Sphingolipid-regulated PCD in plant cells has long been studied, but the biochemical mechanism of its regulation remains largely unclear [6].

No maize genotypes resistant or immune to Fusarium infection and FB contamination have been identified so far [49]. Recently, some plant gene networks were shown to reduce the negative effect of $F$. verticillioides or FBs on plant health; notwithstanding the fact that a high number of markers of resistance was identified, the small effect of each marker on disease severity is consistent with the quantitative nature of the F. verticillioides-maize pathosystem [50]. Here we explored the impact of FBs on the production of plant hormones SA and JA, which are two key effectors of plant defense (Figure $6 a, b)$. In general, the SAmediated defenses act against pathogens with a biotrophic lifestyle, whereas JA-mediated defenses act against necrotrophic pathogens. From our results, we suggest that the balance between SA and JA is fundamental during the infection progress because the increase or decrease of these hormones could influence the success of the pathogen. SA was detected through days 2-14 of the infection (Figure 6a), while JA was detected through days 7-14 of our infection assay (Figure 6b). These results show the timing of hormone accumulation correlate with the transition from a biotrophic growth to a necrotrophic lifestyle for $F$. verticillioides. SA pathway is generally known to be antagonistic to JA pathway, and they turn on/off in response to the lifestyle of the pathogen present. To contain biotrophic growth in general, SA induces an oxidative burst and activates defense-related genes PR1, PR2, and PR5, as well as genes involved in the flavonoid synthesis (e.g. PAL) [51]. Because F. verticillioides is considered a hemibiotrophic pathogen, we suggest that the activation of the JA signaling pathway follows the activation of SA-mediated pathways. The JA pathway promotes the expression of JAs biosynthesis-related genes such as the lipoxygenase (LOX), allene oxide synthase (AOS), allene oxide cyclase (AOC), OPDA reductase (oxo-phytodienoic acid - OPR3) [52]. Here we found that the presence of the FBs quantitatively influenced hormone production; in absence of this mycotoxin (as shown in the mutant-infection assay) the synthesis of JA and SA in seedlings was halved in the final step of infection (14 dai).

Taken together, the data support the hypothesis that fumonisins produced by $F$. verticillioides hijack lipid (sphingolipid) metabolism of maize seedlings, which, in turn, affect host defense by impacting hormone synthesis (SA/JA), driving the cells toward the PCD. Similarly, the effector ToxA produced by Parastagonospora nodorum's elicits PCD in wheat leaves, which also likely aids the switch from an epiphytic to a necrotrophic growth [53]. Thus, by comparison, fumonisins could also be effectors that likely support the necrotrophic stage of F. verticillioides during growth in maize.

\section{Materials and Methods}

\subsection{Fusarium verticillioides Strains and Culture Conditions}

Fungal strains used in this study were Fusarium verticillioides 7600 (ATCC ${ }^{\circledR}$ MYA4922TM) supplied by American Type Culture Collection (ATCC, Manassas, VA, USA) and the fum 1 deletion mutant (fum1 $\triangle$ ), which was derived from 7600 . Fum1 encodes the polyketide synthase responsible for synthesizing the fumonisin carbon backbone [54]. The mutant strain was supplied from the MycoBank of Agricultural Research Service (US Department of Agriculture, Peoria, IL, USA). For general spore production, strains were cultured on potato dextrose broth medium (PDB, Difco, Waltham, MA, USA). Liquid media was inoculated with a suspension of $1 \times 10^{6}$ conidia per $\mathrm{mL}$ and incubated at $25^{\circ} \mathrm{C}$ in the dark on a rotary shaker. Mycelia were harvested five days post-inoculation, filtered, lyophilized, and ground to a powder in liquid nitrogen using a mortar and pestle.

\subsection{Kernel Infection Assay}

The kernel infection assay was performed as described in Covarelli et al. (2012) [55], with some modifications. Maize kernels (maize hybrid KXB6567 distributed by KWS Italia 
S.p.A.) were surface sterilized by immersion for $10 \mathrm{~min}$ in a $1 \%$ of sodium hypochlorite solution. Seeds were then rinsed two times for $10 \mathrm{~min}$ with sterile water and incubated for four hours with sterile water to cover them. The kernels were then pierced with a needle in the embryo area and immersed for $30 \mathrm{~min}$ in sterile water containing $10^{6}$ microconidia per $\mathrm{mL}$ and placed on filter paper saturated with sterile water in Petri dishes. Two Petri dishes containing 10 seeds each were used for each strain and mock-inoculated seeds were used as the control. The kernels (mock and infected) were incubated for 2, 4, 7, and 14 days at which point the number of necrotic roots and the length of the roots and shoots were determined. The assay was repeated in triplicate.

\subsection{HPLC-MS/MS Analysis}

All solvents used for sphingolipids extraction and HPLC/MS analysis were of HPLC/MS grade. Methanol $(\mathrm{MeOH})$, isopropyl alcohol $(\mathrm{iPrOH})$, ethyl acetate (EtOAc), and acetonitrile $(\mathrm{ACN})$ were purchased from Merck (Darmstadt, Germany). Ammonium formate $\left(\mathrm{NH}_{4} \mathrm{HCO}_{2}\right)$ was purchased from Sigma Aldrich.

Mass spectrometry analyses were performed by LC (HPLC 1200 series rapid resolution) coupled to a triple quadrupole MS (G6420 series triple quadrupole, QqQ; Agilent Technologies, Santa Clara, CA, USA), with an electrospray ionization source (ESI). Chromatographic column and analysis software were provided by Agilent Technologies (Santa Clara, CA, USA). The temperature was set at $350{ }^{\circ} \mathrm{C}$, the nitrogen flow at $10 \mathrm{~L} / \mathrm{min}$, the nebulization pressure at $20 \mathrm{psi}$, and the voltage at $4000 \mathrm{~V}$.

\subsubsection{Sphingolipids, Oxylipin, and Fatty Acid Extraction and Analysis}

Lipids were extracted from $30 \mathrm{mg}$ of ground, lyophilized germinated maize kernels, as reported in Ludovici et al. (2014) [44], with some modifications. The internal reference standard added for sphingolipid analysis was the C16:0-d31 ceramide N-palmitoyl-Derythro-sphingosine (Avanti Polar Lipids, Alabaster, AL, USA), while for fatty acid and oxylipin analysis was the oxylipin 9(S)-HODE-d4 (Cayman, Ann Arbor, MI, USA) at the final concentration of $1 \mu \mathrm{M}$. The samples were mixed with $2 \mathrm{~mL}$ of extraction mixture (isopropyl alcohol: water: ethyl acetate 1:1:3 $v / v$, with $0.0025 \% \mathrm{w} / \mathrm{v}$ of butylated hydroxytoluene to prevent peroxidation) and then centrifuged at $12.000 \mathrm{rpm}$. The upper phase was collected and dried under a stream of nitrogen gas. The sample was then extracted with 1 $\mathrm{mL}$ of ethyl acetate. After centrifugation at $12.000 \mathrm{rpm}$, the upper phase was transferred to the collection tube with the first extract and dried under a stream of nitrogen gas. The combined extracts were dissolved in $100 \mu \mathrm{L}$ of methanol and analyzed by HPLC-MS/MS.

Chromatographic separation of sphingolipids was performed with a Zorbax SB-C8 rapid resolution HT $2.1 \times 50$ mm $1.8 \mu \mathrm{m} 600$ bar column (Agilent Technologies, Santa Clara, CA, USA). The mobile phases consisted of A phase (water: B phase 40:60 v/v, containing ammonium formate $5 \mathrm{mM}$ ), B phase (methanol: acetonitrile: isopropyl alcohol 70:20:10 $v / v)$. The elution program was as follows: $0-6 \mathrm{~min} 20 \% \mathrm{~B}, 6-14 \mathrm{~min} 98 \% \mathrm{~B}, 14-18 \mathrm{~min}$ $98 \%$ B, $18-20$ min $100 \%$ B, $18-20$ min $100 \%$ B, 20-22 min 100\% B, 22-26 min $20 \%$ B, and $26-28 \mathrm{~min} 20 \% \mathrm{~B}$. The flow rate was $0.6 \mathrm{~mL} / \mathrm{min}$. The column was warmed at $60{ }^{\circ} \mathrm{C}$. The injection volume was $10 \mu \mathrm{L}$. HPLC-MS/MS method to identify the molecular structures of sphingolipids from biological sources was previously introduced by Sugawara et al. (2010) [56]. Sphingolipids were identified using multiple reaction monitoring (MRM) (Figure S1).

The chromatographic separation of oxylipins and fatty acids was performed with a Zorbax ECLIPSE XDB-C18 rapid resolution HT $4.6 \times 50 \mathrm{~mm} 1.8 \mu \mathrm{m}$ column (Agilent technologies, Santa Clara, CA, USA. The mobile phase consisted of A: water/acetonitrile $97: 3 v / v$ containing $0.1 \%$ formic acid and $3 \%$ acetonitrile, and B: acetonitrile/isopropyl alcohol 90:10 $\mathrm{v} / \mathrm{v}$. The elution program was: $0-2 \mathrm{~min} 80 \% \mathrm{~A}$ and $20 \% \mathrm{~B}, 2-4 \mathrm{~min} 65 \% \mathrm{~A}$ $35 \% \mathrm{~B}, 4-6 \mathrm{~min} 60 \% \mathrm{~A}$ and $40 \% \mathrm{~B}, 6-7 \mathrm{~min} 58 \% \mathrm{~A}$ and $42 \%, 7-9 \min 52 \% \mathrm{~A}$ and $48 \% \mathrm{~B}$, 9-15 $\min 35 \% \mathrm{~A}$ and $65 \% \mathrm{~B}, 15-17 \mathrm{~min} 25 \% \mathrm{~A}$ and $75 \% \mathrm{~B}, 17-18.50 \mathrm{~min} 15 \% \mathrm{~A}$ and $85 \% \mathrm{~B}$, $18.50-19.50 \mathrm{~min} 5 \% \mathrm{~A}$ and $95 \% \mathrm{~B}, 19.50-24 \mathrm{~min} 5 \% \mathrm{~A}$ and $95 \% \mathrm{~B}, 24-26 \mathrm{~min} 1 \% \mathrm{~A}$ and $99 \%$ 
$\mathrm{B}, 26-30 \mathrm{~min} 1 \% \mathrm{~A}$ and $99 \% \mathrm{~B}, 30-34 \mathrm{~min} 80 \% \mathrm{~A}$ and $20 \% \mathrm{~B}$. The flow rate was: $0-24 \mathrm{~min}$ at $0.6 \mathrm{~mL} / \mathrm{min}, 24-30 \mathrm{~min}$ at $1 \mathrm{~mL} / \mathrm{min}, 30-34 \mathrm{~min}$ at $0.6 \mathrm{~mL} / \mathrm{min}$. The column temperature was set at $50{ }^{\circ} \mathrm{C}$ with an injection volume of $10 \mu \mathrm{L}$. Oxylipins present were identified using MRM [44], while fatty acids were identified using the single ion monitoring (SIM) approach (Figure S1).

\subsubsection{Fumonisin Extraction and Analysis}

FBs were extracted from F. verticillioides infected and non-infected maize kernels. A total of $500 \mathrm{mg}$ of lyophilized seedling roots and shoots was ground in presence of liquid nitrogen with a mortar and pestle. The internal standard $\left[{ }^{13} \mathrm{C}_{34}\right]$ fumonisin $\mathrm{B}_{1}$ (Romer Labs, Getzersrdorf, Austria) was added at the final concentration of $2 \mu \mathrm{M}$. FBs were extracted with a method described by Agilent Technologies (Santa Clara, CA, USA) with some modification [57]. A total of $2 \mathrm{~mL}$ of acetonitrile: water: acetic acid (70:29:1, v/v/v) was added to the ground plant material, vortexed for $1 \mathrm{~min}$, and placed on a rotary shaker for $30 \mathrm{~min}$. The solution was centrifuged at $7.000 \mathrm{rpm}$ for $15 \mathrm{~min}$. The supernatant was collected and dried under oxygen gas flux. The dried samples were resuspended in $100 \mu \mathrm{L}$ of acetonitrile.

Chromatographic separation of fumonisins was performed with a Zorbax ECLIPSE XDB-C18 rapid resolution HT $4.6 \times 50$ mm $1.8 \mu \mathrm{m}$ column (Agilent Technologies, Santa Clara, CA, USA) and was used at $25^{\circ} \mathrm{C}$, and the injected volume was $5 \mu \mathrm{L}$. The mobile phases consisted of A: water: methanol: acetic acid (89:10:1, v/v/v) containing $5 \mathrm{mM}$ of ammonium acetate, and B: methanol: water: acetic acid $(2: 97: 1, v / v / v)$ containing $5 \mathrm{mM}$ of ammonium acetate. The elution gradient was as follows: 0-2 min 1\% B, 3-14 min 99\% B, 15-18 $\min 99 \% \mathrm{~B}, 19-20 \mathrm{~min} 1 \% \mathrm{~B}$. The gradient was followed by $2 \mathrm{~min}$ for re-equilibration. The flowrate was constant at $0,6 \mathrm{~mL} / \mathrm{min}$. The main transition and qualifier ions for $\mathrm{FB}_{1}$ is $722.2 \rightarrow 352.1$, for $\mathrm{FB}_{2}$ is $706.4 \rightarrow 336.3$, and for the internal standard $\left[13 \mathrm{C}_{34}\right] \mathrm{FB}_{1}$ is $756.4 \rightarrow 374.4$. Fragmentor was set at $180 \mathrm{~V}$ and the collision energy at $45 \mathrm{eV}$. Quantitation of $\mathrm{FB}_{1}$ and $\mathrm{FB}_{2}$ in maize samples was calculated using a linear calibration curve covering a concentration range of $0.025-50 \mathrm{ng} / \mathrm{mL}$. The equation for $\mathrm{FB}_{1}$ was $\mathrm{y}=515,27 \mathrm{x}+47,246$ $\left(R^{2}=0.9951\right)$ and the equation for $\mathrm{FB}_{2}$ was $y=5465,9 x+72,908\left(R^{2}=0.9959\right)$.

\subsubsection{SA and JA Extraction and Analysis}

SA was extracted from $F$. verticillioides infected and mock-infected maize seedlings, essentially as described in Antiga et al. (2020) [58]. The quantification was carried out by the addition of internal standard 1-naphthaleneacetic acid (NAA), at a final concentration of $5 \mu \mathrm{M}$. A total of $30 \mathrm{mg}$ of lyophilized, ground mycelium was extracted with $750 \mu \mathrm{L}$ of methanol: water: acetic acid $(90: 9: 1, v / v / v)$. Extraction was repeated and the dried samples were dissolved in $200 \mu \mathrm{L}$ of a mixture of water and acetic acid (0.05\%). Chromatographic separation was carried out with a Zorbax ECLIPSE XDB-C18 rapid resolution HT $4.6 \times 50 \mathrm{~mm} 1.8 \mu \mathrm{m}$ p.s. column (Agilent Technologies, Santa Clara, CA, USA), and the column was thermostated at $25^{\circ} \mathrm{C}$ and $10 \mu \mathrm{L}$ were injected. The mobile phases consisted of A: water containing $0.05 \%$ acetic acid, and $\mathrm{B}$ : acetonitrile. The elution gradient was as follows: $0-3 \mathrm{~min} 15 \% \mathrm{~B}, 3-5 \mathrm{~min} 100 \% \mathrm{~B}, 5-6 \mathrm{~min} 100 \% \mathrm{~B}, 6-7 \mathrm{~min} 15 \% \mathrm{~B}$, and $7-8 \mathrm{~min} 15 \%$ $\mathrm{B}$. The gradient was followed by $5 \mathrm{~min}$ of the original mobile phase for re-equilibration. The flow-rate was constant at $0.6 \mathrm{~mL} / \mathrm{min}$. SA was analyzed in negative ion mode $[\mathrm{M}+\mathrm{H}]^{-}$. The main transition for SA was $137.2 \rightarrow 92.9$ and the main transition for JA was $209.2 \rightarrow 59.9$. The internal standard NAA was analyzed in negative ion mode as the acetate adduct [M $\left.+\mathrm{CH}_{3} \mathrm{COOH}^{-}\right]^{-}$. The main transition for NAA was $245 \rightarrow 180.8$. For SA, the fragmentor was kept at $135 \mathrm{~V}$ and the collision energy was $20 \mathrm{eV}$, and for NAA, the fragmentor was kept at $100 \mathrm{~V}$ and the collision energy was $16 \mathrm{eV}$. SA and JA were identified using MRM in negative ion mode $[\mathrm{M}-\mathrm{H}]^{-}$. 


\subsection{Nucleic Acid Manipulation: DNA for qPCR Analysis}

For qPCR, lyophilized germinated seedlings were ground in a blender with liquid nitrogen. Total genomic DNAs were extracted from $30 \mathrm{mg}$ of material employing the 3-CTAB method as previously described [59]. DNA concentration was assessed with the Nanodrop spectrophotometer (Thermo Fisher Scientific, Waltham, MA, USA) and confirmed by agarose gel electrophoresis. qPCR assays were performed using the primer pairs specific to F. verticillioides $\beta$-tubulin and Z. mays $\beta$-tubulin (Table 2). Amplifications were performed in $10 \mu \mathrm{L}$ of SensiFAST ${ }^{\mathrm{TM}} \mathrm{SYBR}^{\circledR}$ No-ROX Kit (Bioline, Memphis, TN, USA) containing $200 \mathrm{ng}$ of DNA. DNA quantification was determined using the $2^{-\Delta \Delta \mathrm{ct}}$ method, i.e., by normalizing the $F$. verticillioides $\beta$-tubulin cycle threshold $(\mathrm{Ct})$ value with the $Z$. mays $\beta$-tubulin $\mathrm{Ct}$ and each value of the infected samples with their relative controls [60].

Table 2. Primers used in this study.

\begin{tabular}{|c|c|c|c|}
\hline Gene & Accession No. & t Annealing $\left({ }^{\circ} \mathrm{C}\right)$ & Sequence \\
\hline \multirow{2}{*}{$\beta$-tubulin } & \multirow{2}{*}{ NP_001105457 } & \multirow{2}{*}{60} & Fw CTACCTCACGGCATCTGCTATGT \\
\hline & & & Rev GTCACACACACTCGACTTCACG \\
\hline \multirow{2}{*}{$\beta$-tubulin } & \multirow{2}{*}{ FVEG_04081 } & \multirow{2}{*}{40} & Fw CTCTGCTCATTTCCAAGATCCGCG \\
\hline & & & Rev GTAGTTGAGGTCACCGTAGGAGG \\
\hline
\end{tabular}

\subsection{Vybrant Assay for PCD Detection}

Fresh maize seeds were surface sterilized by immersion in $1 \%$ of sodium hypochlorite for $10 \mathrm{~min}$ and rinsed two times for $10 \mathrm{~min}$ with sterile water. Seeds were allowed to germinate for 4 days, as described above. To release protoplasts, $1 \mathrm{gm}$ of germinated maize kernels from each treatment was suspended in a $30 \mathrm{~mL}$ solution containing the cell wall degrading enzymes Extralyse ${ }^{\circledR}(1.5 \%)$, Cellulase (Merck KGaA, Darmstadt, Germany) $(0.5 \%)$ and Driselase $(0.3 \%)$. A total of $10^{6}$ protoplasts were treated for $30 \mathrm{~min}$ with a mixture of $25 \mathrm{ng}$ of $\mathrm{FB}_{1}$ and $\mathrm{FB}_{2}$ and were analyzed with the Vybrant apoptosis assay (Thermo Fisher Scientific, Waltham, MA, USA). Viable, necrotic, and apoptotic protoplasts present in the same sample were distinguished from each other by evaluating differences in cell membrane permeability and were counted using the epifluorescence motorized microscope Zeiss Imager M2 controlled by Zen pro (Carl Zeiss, Aalen, Germany) [61].

\subsection{Statistical Analysis}

Error bars represent the standard error calculated from independent replicates, technically repeated in triplicate. Rstudio was used as the statistic package. Datasets are compared using one- or two-way ANOVA followed by Tukey's test. Other datasets were compared using Student's t-test.

\section{Conclusions}

Our analyses indicate fumonisin as a virulence factor, demonstrating that during the infection process the accumulation of FB generates an alteration of lipid metabolism.

This study demonstrated that both FAs and S-LCFA increase in presence of FBs, causing the activation of the defense directing the seedlings toward PCD, as underlined by the presence of sphingosine d18:1 [21]. The increase of hormone synthesis (SA and JA) indicates the infection progress, suggesting the fundamental role of these molecules.

Moreover, the seedlings infected by wild-type strain are affected in the S-VLCFA accumulation [62]. Taken together, our results provided a basis for better understanding the lipid markers of PCD caused by the mycotoxigenic fungus F. verticillioides (Figure 7). 


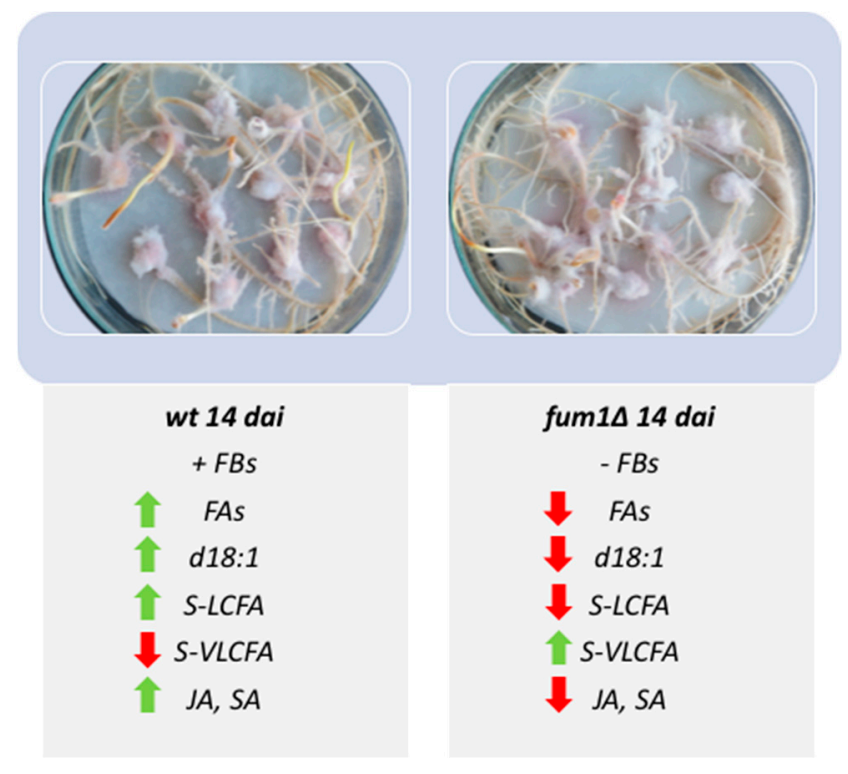

Figure 7. Seedlings infected at 14 dai with F. verticillioides wild-type (wt) or fum 1 deletion mutant (fum1 1 ) strains. Lipids, hormones, and genes are accompanied by the green or red arrow to indicate the relative increase or decrease.

Supplementary Materials: Supplementary materials can be found at https://www.mdpi.com/1422 $-0067 / 22 / 5 / 2435 / s 1$.

Author Contributions: Conceptualization, M.R. and V.S.; methodology, M.R., M.L., and M.B.; software, M.B. and M.S.; validation, M.R. and V.S.; formal analysis, M.B.; investigation, M.B., M.S., A.C., and S.D.; resources, M.R., M.B., and M.S.; data curation, M.B. and M.S.; writing-original draft preparation, M.B.; writing-review and editing, M.R., V.S., and D.W.B.; visualization, M.B. and M.S.; supervision, M.R.; project administration, M.R.; funding acquisition, M.R. All authors have read and agreed to the published version of the manuscript.

Funding: This research received no external funding.

Institutional Review Board Statement: Not applicable.

Informed Consent Statement: Not applicable.

Data Availability Statement: Data is contained within the article or supplementary material.

Acknowledgments: The authors thank the Sapienza University for providing laboratory space, the Agriculture Research Service for providing the fungal strains, and the Dott. Massimo Blandino (University of Turin) for providing the maize kernels.

Conflicts of Interest: Matteo Ludovici is currently employed by Agilent technologies. All other authors declare no competing interests.

\begin{tabular}{ll}
\multicolumn{2}{l}{ Abbreviations } \\
CerS & Ceramide Synthase \\
$\mathrm{CH}_{3} \mathrm{COOH}$ & Acetic Acid \\
DAI & Day after inoculation \\
DOAJ & Directory of open access journals \\
FA & Fatty Acid \\
FB & Fumonisin \\
Fum1 $1 \Delta$ & FB non-producing mutant \\
JA & Jasmonic Acid \\
LCB & Long Chain Base \\
LCFA & Long Chain Fatty Acid \\
LOH1 & Ceramide Synthase 1 \\
LOH2 & Ceramide Synthase 2 \\
LOH3 & Ceramide Synthase 3
\end{tabular}




$\begin{array}{ll}\text { MDPI } & \text { Multidisciplinary Digital Publishing Institute } \\ \text { MRM } & \text { Multiple Reaction Monitoring } \\ \text { NAA } & \text { 1-naphthaleneacetic acid } \\ \text { PCD } & \text { Plant Cell Death } \\ \text { PUFA } & \text { Polyunsaturated Fatty Acid } \\ \text { SA } & \text { Salicylic Acid } \\ \text { SIM } & \text { Single Ion Monitoring } \\ \text { VLCFA } & \text { Very Long Chain Fatty Acid }\end{array}$

\section{References}

1. Divon, H.H.; Fluhr, R. Nutrition acquisition strategies during fungal infection of plants. FEMS Microbiol. Lett. 2007, 266, 65-74. [CrossRef]

2. Oliver, R.P.; Ipcho, S.V.S. Arabidopsis pathology breathes new life into the necrotrophs-vs.-biotrophs classification of fungal pathogens. Mol. Plant Pathol. 2004, 5, 347-352. [CrossRef]

3. Maiorano, A.; Reyneri, A.; Sacco, D.; Magni, A.; Ramponi, C. A dynamic risk assessment model (FUMAgrain) of fumonisin synthesis by Fusarium verticillioides in maize grain in Italy. Crop Prot. 2009, 28, 243-256. [CrossRef]

4. Leslie, J.F.; Summerell, B.A. The Fusarium Laboratory Manual; John Wiley \& Sons: Hoboken, NJ, USA, 2008 ; ISBN 0470276460.

5. Rai, M.; Agarkar, G. Plant-fungal interactions: What triggers the fungi to switch among lifestyles? Crit. Rev. Microbiol. 2016, 42, 428-438. [CrossRef] [PubMed]

6. Wang, E.; Norred, W.P.; Bacon, C.W.; Riley, R.T.; Merrill, A.H. Inhibition of sphingolipid biosynthesis by fumonisins. Implications for diseases associated with Fusarium moniliforme. J. Biol. Chem. 1991, 266, 14486-14490. [CrossRef]

7. Abbas, H.K.; Tanaka, T.; Duke, S.O.; Porter, J.K.; Wray, E.M.; Hodges, L.; Sessions, A.E.; Wang, E.; Merrill, A.H., Jr.; Riley, R.T. Fumonisin-and AAL-toxin-induced disruption of sphingolipid metabolism with accumulation of free sphingoid bases. Plant Physiol. 1994, 106, 1085-1093. [CrossRef] [PubMed]

8. Gilchrist, D.G.; Bostock, R.M.; Wang, H. Sphingosine-related mycotoxins in plant and animal diseases. Can. J. Bot. 1995, 73 (Suppl. 1), 459-467. [CrossRef]

9. Yoo, H.S.; Norred, W.P.; Showker, J.; Riley, R.T. Elevated sphingoid bases and complex sphingolipid depletion as contributing factors in fumonisin-induced cytotoxicity. Toxicol. Appl. Pharmacol. 1996, 138, 211-218. [CrossRef] [PubMed]

10. Desjardins, A.E.; Plattner, R.D. Fumonisin B1-nonproducing strains of Fusarium verticillioides cause maize (Zea mays) ear infection and ear rot. J. Agric. Food Chem. 2000, 48, 5773-5780. [CrossRef]

11. Williams, L.D.; Glenn, A.E.; Zimeri, A.M.; Bacon, C.W.; Smith, M.A.; Riley, R.T. Fumonisin disruption of ceramide biosynthesis in maize roots and the effects on plant development and Fusarium verticillioides-induced seedling disease. J. Agric. Food Chem. 2007, 55, 2937-2946. [CrossRef]

12. Bacon, C.W.; Glenn, A.E.; Yates, I.E. Fusarium verticillioides: Managing the endophytic association with maize for reduced fumonisins accumulation. Toxin Rev. 2008, 27, 411-446. [CrossRef]

13. Van Hove, F.; Waalwijk, C.; Logrieco, A.; Munaut, F.; Moretti, A. Gibberella musae (Fusarium musae) sp. nov., a recently discovered species from banana is sister to F. verticillioides. Mycologia 2011, 103, 570-585. [CrossRef] [PubMed]

14. Sun, L.; Chen, X.; Gao, J.; Zhao, Y.; Liu, L.; Hou, Y.; Wang, L.; Huang, S. Effects of disruption of five FUM Genes on Fumonisin biosynthesis and pathogenicity in Fusarium proliferatum. Toxins 2019, 11, 327. [CrossRef]

15. Futerman, A.H. Inhibition of sphingolipid synthesis: Effects on glycosphingolipid- GPI-anchored protein microdomains. Trends Cell Biol. 1995, 5, 377-380. [CrossRef]

16. Spiegel, S.; Merrill, A.H. Sphingolipid metabolism and cell growth regulation. FASEB J. 1996, 10, 1388-1397. [CrossRef] [PubMed]

17. Beccaccioli, M.; Reverberi, M.; Scala, V. Fungal lipids: Biosynthesis and signalling during plant-pathogen interaction. Front. Biosci.-Landmark 2019, 24, 172-185.

18. Merrill, A.H., Jr.; Sullards, M.C.; Allegood, J.C.; Kelly, S.; Wang, E. Sphingolipidomics: High-throughput, structure-specific, and quantitative analysis of sphingolipids by liquid chromatography tandem mass spectrometry. Methods 2005, 36, 207-224. [CrossRef]

19. Wolpert, T.J.; Dunkle, L.D.; Ciuffetti, L.M. Host-selective toxins and avirulence determinants: What's in a name? Annu. Rev. Phytopathol. 2002, 40, 251-285. [CrossRef]

20. Kim, H.-S.; Lohmar, J.M.; Busman, M.; Brown, D.W.; Naumann, T.A.; Divon, H.H.; Uhlig, S.; Proctor, R.H. Identification and distribution of gene clusters required for synthesis of sphingolipid metabolism inhibitors in diverse species of the filamentous fungus Fusarium. BMC Genomics 2020, 21, 1-24.

21. Shi, L.; Bielawski, J.; Mu, J.; Dong, H.; Teng, C.; Zhang, J.; Yang, X.; Tomishige, N.; Hanada, K.; Hannun, Y.A.; et al. Involvement of sphingoid bases in mediating reactive oxygen intermediate production and programmed cell death in Arabidopsis. Cell Res. 2007, 17, 1030-1040. [CrossRef] [PubMed]

22. Asai, T.; Stone, J.M.; Heard, J.E.; Kovtun, Y.; Yorgey, P.; Sheen, J.; Ausubel, F.M. Fumonisin B1-induced cell death in Arabidopsis protoplasts requires jasmonate-, ethylene-, and salicylate-dependent signaling pathways. Plant Cell 2000, 12, 1823-1835. [PubMed]

23. Nishimura, M.T.; Stein, M.; Hou, B.H.; Vogel, J.P.; Edwards, H.; Somerville, S.C. Loss of a callose synthase results in salicylic acid-dependent disease resistance. Science 2003, 301, 969-972. [CrossRef] [PubMed] 
24. Sánchez-Rangel, D.; Sánchez-Nieto, S.; Plasencia, J. Fumonisin B1, a toxin produced by Fusarium verticillioides, modulates maize $\beta-1,3$-glucanase activities involved in defense response. Planta 2012, 235, 965-978. [CrossRef]

25. Liang, H.; Yao, N.; Song, J.T.; Luo, S.; Lu, H.; Greenberg, J.T. Ceramides modulate programmed cell death in plants. Genes Dev. 2003, 17, 2636-2641. [CrossRef]

26. Berkey, R.; Bendigeri, D.; Xiao, S. Sphingolipids and plant defense/disease: The "death" connection and beyond. Front. Plant Sci. 2012, 3, 68. [CrossRef]

27. Markham, J.E.; Molino, D.; Gissot, L.; Bellec, Y.; Hématy, K.; Marion, J.; Belcram, K.; Palauqui, J.-C.; Satiat-JeuneMaître, B.; Faure, J.-D. Sphingolipids containing very-long-chain fatty acids define a secretory pathway for specific polar plasma membrane protein targeting in Arabidopsis. Plant Cell 2011, 23, 2362-2378. [CrossRef]

28. De Zutter, N.; Audenaert, K.; Ameye, M.; De Boevre, M.; De Saeger, S.; Haesaert, G.; Smagghe, G. The plant response induced in wheat ears by a combined attack of Sitobion avenae aphids and Fusarium graminearum boosts fungal infection and deoxynivalenol production. Mol. Plant Pathol. 2017, 18, 98-109. [CrossRef]

29. Ali, S.; Ganai, B.A.; Kamili, A.N.; Bhat, A.A.; Mir, Z.A.; Bhat, J.A.; Tyagi, A.; Islam, S.T.; Mushtaq, M.; Yadav, P. Pathogenesisrelated proteins and peptides as promising tools for engineering plants with multiple stress tolerance. Microbiol. Res. 2018, 212, 29-37. [CrossRef]

30. Liu, L.; Sonbol, F.-M.; Huot, B.; Gu, Y.; Withers, J.; Mwimba, M.; Yao, J.; He, S.Y.; Dong, X. Salicylic acid receptors activate jasmonic acid signalling through a non-canonical pathway to promote effector-triggered immunity. Nat. Commun. 2016, 7, 1-10. [CrossRef]

31. Walley, J.W.; Kliebenstein, D.J.; Bostock, R.M.; Dehesh, K. Fatty acids and early detection of pathogens. Curr. Opin. Plant Biol. 2013, 16, 520-526. [CrossRef] [PubMed]

32. Trépanier, M.; Bécard, G.; Moutoglis, P.; Willemot, C.; Gagné, S.; Avis, T.J.; Rioux, J.-A. Dependence of arbuscular-mycorrhizal fungi on their plant host for palmitic acid synthesis. Appl. Environ. Microbiol. 2005, 71, 5341-5347. [CrossRef]

33. Xing, J.; Chin, C.-K. Modification of fatty acids in eggplant affects its resistance to Verticillium dahliae. Physiol. Mol. Plant Pathol. 2000, 56, 217-225. [CrossRef]

34. Kachroo, A.; Shanklin, J.; Whittle, E.; Lapchyk, L.; Hildebrand, D.; Kachroo, P. The Arabidopsis stearoyl-acyl carrier proteindesaturase family and the contribution of leaf isoforms to oleic acid synthesis. Plant Mol. Biol. 2007, 63, 257-271. [CrossRef] [PubMed]

35. Oldenburg, E.; Höppner, F.; Ellner, F.; Weinert, J. Fusarium diseases of maize associated with mycotoxin contamination of agricultural products intended to be used for food and feed. Mycotoxin Res. 2017, 33, 167-182. [CrossRef]

36. Scala, V.; Giorni, P.; Cirlini, M.; Ludovici, M.; Visentin, I.; Cardinale, F.; Fabbri, A.A.; Fanelli, C.; Reverberi, M.; Battilani, P.; et al. LDS1-produced oxylipins are negative regulators of growth, conidiation and fumonisin synthesis in the fungal maize pathogen Fusarium verticillioides. Front. Microbiol. 2014, 5, 669. [CrossRef] [PubMed]

37. Dall'Asta, C.; Falavigna, C.; Galaverna, G.; Battilani, P. Role of maize hybrids and their chemical composition in Fusarium infection and fumonisin production. J. Agric. Food Chem. 2012, 60, 3800-3808. [CrossRef] [PubMed]

38. Christensen, S.A.; Kolomiets, M.V. The lipid language of plant-fungal interactions. Fungal Genet. Biol. 2011, 48, 4-14. [CrossRef]

39. Dall'Asta, C.; Giorni, P.; Cirlini, M.; Reverberi, M.; Gregori, R.; Ludovici, M.; Camera, E.; Fanelli, C.; Battilani, P.; Scala, V. Maize lipids play a pivotal role in the fumonisin accumulation. World Mycotoxin J. 2015, 8, 87-97. [CrossRef]

40. Gao, X.; Kolomiets, M. V Host-derived lipids and oxylipins are crucial signals in modulating mycotoxin production by fungi. Toxin Rev. 2009, 28, 79-88. [CrossRef]

41. Cronjé, M.J.; Weir, I.E.; Bornman, L. Salicylic acid-mediated potentiation of Hsp70 induction correlates with reduced apoptosis in tobacco protoplasts. Cytom. Part A J. Int. Soc. Anal. Cytol. 2004, 61, 76-87. [CrossRef] [PubMed]

42. Jardine, D.J.; Leslie, J.F. Aggressiveness to mature maize plants of Fusarium strains differing in ability to produce fumonisin. Plant Dis. 1999, 83, 690-693. [CrossRef]

43. Desjardins, A.E.; Munkvold, G.P.; Plattner, R.D.; Proctor, R.H. FUM1-A gene required for fumonisin biosynthesis but not for maize ear rot and ear infection by Gibberella moniliformis in field tests. Mol. Plant Microbe Interact. 2002, 15, 1157-1164. [CrossRef]

44. Ludovici, M.; Ialongo, C.; Reverberi, M.; Beccaccioli, M.; Scarpari, M.; Scala, V. Quantitative profiling of oxylipins through comprehensive LC-MS/MS analysis of Fusarium verticillioides and maize kernels. Food Addit. Contam. Part A Chem. Anal. Control. Expo. Risk Assess. 2014, 31, 2026-2033. [CrossRef] [PubMed]

45. Arias, S.L.; Theumer, M.G.; Mary, V.S.; Rubinstein, H.R. Fumonisins: Probable role as effectors in the complex interaction of susceptible and resistant maize hybrids and Fusarium verticillioides. J. Agric. Food Chem. 2012, 60, 5667-5675. [CrossRef] [PubMed]

46. Siebers, M.; Brands, M.; Wewer, V.; Duan, Y.; Hölzl, G.; Dörmann, P. Lipids in plant-microbe interactions. Biochim. Biophys. Acta-Mol. Cell Biol. Lipids 2016, 1861, 1379-1395. [CrossRef]

47. Zitomer, N.C.; Glenn, A.E.; Bacon, C.W.; Riley, R.T. A single extraction method for the analysis by liquid chromatography/tandem mass spectrometry of fumonisins and biomarkers of disrupted sphingolipid metabolism in tissues of maize seedlings. Anal. Bioanal. Chem. 2008, 391, 2257-2263. [CrossRef] [PubMed]

48. Michaelson, L.V.; Napier, J.A.; Molino, D.; Faure, J.D. Plant sphingolipids: Their importance in cellular organization and adaption. Biochim. Biophys. Acta-Mol. Cell Biol. Lipids 2016, 1861, 1329-1335. [CrossRef]

49. Stagnati, L.; Rahjoo, V.; Samayoa, L.F.; Holland, J.B.; Borrelli, V.M.G.; Busconi, M.; Lanubile, A.; Marocco, A. A Genome-wide association study to understand the effect of Fusarium verticillioides infection on seedlings of a maize diversity panel. G3 Genes, Genomes, Genet. 2020, 10, 1685-1696. [CrossRef] 
50. Stagnati, L.; Lanubile, A.; Samayoa, L.F.; Bragalanti, M.; Giorni, P.; Busconi, M.; Holland, J.B.; Marocco, A. A genome wide association study reveals markers and genes associated with resistance to Fusarium verticillioides infection of seedlings in a maize diversity panel. G3 Genes, Genomes, Genet. 2019, 9, 571-579. [CrossRef]

51. Ding, L.; Xu, H.; Yi, H.; Yang, L.; Kong, Z.; Zhang, L.; Xue, S.; Jia, H.; Ma, Z. Resistance to hemi-biotrophic F. graminearum infection is associated with coordinated and ordered expression of diverse defense signaling pathways. PLoS ONE 2011, 6, e19008. [CrossRef] [PubMed]

52. Ruan, J.; Zhou, Y.; Zhou, M.; Yan, J.; Khurshid, M.; Weng, W.; Cheng, J.; Zhang, K. Jasmonic acid signaling pathway in plants. Int. J. Mol. Sci. 2019, 20, 2479. [CrossRef] [PubMed]

53. Vincent, D.; Du Fall, L.A.; Livk, A.; Mathesius, U.; Lipscombe, R.J.; Oliver, R.P.; Friesen, T.L.; Solomon, P.S. A functional genomics approach to dissect the mode of action of the Stagonospora nodorum effector protein SnToxA in wheat. Mol. Plant Pathol. 2012, 13, 467-482. [CrossRef]

54. Proctor, R.H.; Desjardins, A.E.; Plattner, R.D.; Hohn, T.M. A polyketide synthase gene required for biosynthesis of fumonisin mycotoxins in Gibberella fujikuroi mating population A. Fungal Genet. Biol. 1999, 27, 100-112. [CrossRef]

55. Covarelli, L.; Stifano, S.; Beccari, G.; Raggi, L.; Lattanzio, V.M.T.; Albertini, E. Characterization of Fusarium verticillioides strains isolated from maize in Italy: Fumonisin production, pathogenicity and genetic variability. Food Microbiol. 2012, 31, 17-24. [CrossRef] [PubMed]

56. Sugawara, T.; Duan, J.; Aida, K.; Tsuduki, T.; Hirata, T. Identification of glucosylceramides containing sphingatrienine in maize and rice using ion trap mass spectrometry. Lipids 2010, 45, 451-455. [CrossRef]

57. Ye, J.; Wu, Y.; Wang, S.; Guo, Q.; Lu, M.; Wu, C.; Chen, Y. Simultaneous determination of 16 mycotoxins in cereals using an Agilent Triple Quadrupole LC/MS system and e-Method. Agil. Technol. 2017, 2017, 1-10.

58. Antiga, L.; La Starza, S.R.; Miccoli, C.; D’Angeli, S.; Scala, V.; Zaccaria, M.; Shu, X.; Obrian, G.; Beccaccioli, M.; Payne, G.A. Aspergillus flavus Exploits maize kernels using an "Orphan" secondary metabolite cluster. Int. J. Mol. Sci. 2020, 21, 8213. [CrossRef] [PubMed]

59. Scala, V.; Grottoli, A.; Cigliano, R.A.; Anzar, I.; Beccaccioli, M.; Fanelli, C.; Dall'Asta, C.; Battilani, P.; Reverberi, M.; Sanseverino, W. Careful with that axe, gene, genome perturbation after a PEG-mediated protoplast transformation in Fusarium verticillioides. Toxins 2017, 9, 183. [CrossRef] [PubMed]

60. Livak, K.J.; Schmittgen, T.D. Analysis of relative gene expression data using real-time quantitative PCR and the $2^{-\Delta \Delta C T}$ method. Methods 2001, 25, 402-408. [CrossRef]

61. D'Angeli, S.; Altamura, M.M. Osmotin induces cold protection in olive trees by affecting programmed cell death and cytoskeleton organization. Planta 2007, 225, 1147-1163. [CrossRef]

62. Zeng, H.-Y.; Li, C.-Y.; Yao, N. Fumonisin B1: A tool for exploring the multiple functions of sphingolipids in plants. Front. Plant Sci. 2020, 11, 600458. [CrossRef] [PubMed] 